\title{
The Research Progress of Hexafluorobutadiene Synthesis
}

\author{
Jing Zhu, Shuang Chen, Baohe Wang, Xiaorong Zhang \\ Research and Development Center of Petrochemical Technology, Tianjin University, Tianjin, China \\ Email: cj_zhu1975@tju.edu.cn
}

Received 21 October 2014; revised 3 December 2014; accepted 19 December 2014

Copyright (C) 2014 by authors and Scientific Research Publishing Inc.

This work is licensed under the Creative Commons Attribution International License (CC BY).

http://creativecommons.org/licenses/by/4.0/

(c) (i) Open Access

\begin{abstract}
Hexafluorobutadiene is a new plasma etching gas for semiconductor molectron which has perfect properties and also is a preceding monomer that can be used for synthesizing many fluorinated compounds. This paper described the different synthesis methods of perflurobutadiene from different materials, and contrasted the characteristic of each synthetic method. The route from tetrafluoroethylene has more industrialization prospects.
\end{abstract}

\section{Keywords}

Perfluorobutadiene, Synthesis, Diiodoperfluoroalkanes, Trifluoromonochloroethylene, Tetrafluoroethylene, 1,2-Difluoro-1',2'-dichloroethylene

\section{Introduction}

Hexafluorobutadiene, which is a fully fluorinated compound with double bonds, has the boiling point of $5.6^{\circ} \mathrm{C}$ and the density of $1.4 \mathrm{~g} / \mathrm{ml}\left(15^{\circ} \mathrm{C}\right)$. It shows a good foreground as monomer in the synthesis process of fluororesins, fluoroplastics and fluororubbers. In addition, it can be copolymerized with other monomers to synthesis high performance fluoroelastomer and resins with excellent electric properties [1]-[3]. However, the present researches on hexafluorobutadiene application focus mainly on dry etching of VLSI, and studies suggest that it is a fine electrical etching gas with high selectivity and accuracy [4]-[7]. So far, only a few companies produce hexafluorobutadiene all over the world because of the difficulties in its preparation. The preparation methods of hexafluorobutadiene are introduced in this article in order to provide some ideas for the industrialized development.

\section{Hexafluorobutadiene Application}

\subsection{Novel Cyanine Dye}

Cyanine dye first appeared in 1856, and it is widely used in synthetic organic chemistry and physical chemistry 
due to its structural variability. Recently, researchers have found emerging applications of cyanine dye in solar energy utilization, for instance, Rensmo [8] indicated that nanocrystalline ZnO electrode, which was sensitized by organic dye, can be used as photo-anodes in photoelectrochemical solar cell, and photoelectric conversion efficiency of the photoelectrochemical solar cell was 2\%. Yagupolskii [9] suggested that a fluorine atom introduced in the connecting bridge could effectively increase the absorbance range of the dye, and Yagupolskii [9] successfully introduced the flooring system into the cyanine dyes via reaction of perfluorobutadiene and benzothiazole, so that the maximum absorption wavelength of the dye was increased from $453 \mathrm{~nm}$ to $578 \mathrm{~nm}$. The synthesis process is mainly divided into three steps: synthesized 2-perfluorobutadiene benzothiazole by the reaction of benzothiazole basic magnesium chloride and perfluorobutadiene in tetrahydrofuran solvent at $-40^{\circ} \mathrm{C}$, and then, prepared N-methyl-2-perfluorobutadiene benzothiazoles boron tetrafluoride salt(I) by the alkylation reaction of 2-perfluorobutadiene benzothiazole with iodomethane under the catalysis of $\mathrm{AgBF}_{4}$. Lastly, the dehydrofluorination reaction of the salt(I) and N-methyl-2-fluorine methylene benzothiazole was conducted to get the cyanine dyes. The specific procedures were as follows (Scheme 1).

\subsection{Plasma Atching Agent}

Recently, many researches had focused on dry etching process of VLSI [10] using hexafluorobutadiene. In the manufacturing process of semiconductor devices, etching process is to use as chemical solvent, corrosive gas or plasma to remove unwanted parts in the wafer or wafer surface layer. Wet etching, which always happened in a chemical solution, conducted isotropic etching reaction under the action of strong acids and can also etch the covered parts. In contrast, dry etching with corrosive gas or plasma ion could realize anisotropic etching in vertical direction on the wafer. Thus, dry etching is applicable to high-precision fine craft, such as large scale integrated circuit (VLSI) etching process.

Hexafluorobutadiene, which is an environmental friendly laser etching gas and just appeared on the market in 2004, etches the line width of $90 \mathrm{~nm}$ or less [11]. Compared with octafluorocyclobutane $\left(\mathrm{C}_{4} \mathrm{~F}_{8}\right)$ which is widely used at present and etches the line width of $130 \mathrm{~nm}$, hexafluorobutadiene has several distinguished features: 1) faster degradation speed in atmosphere. $\mathrm{C}_{4} \mathrm{~F}_{6}$ can be degraded in two days while $\mathrm{C}_{4} \mathrm{~F}_{8}$ requires 3200 years; 2) lower greenhouse effect. Greenhouse effect produced by $\mathrm{C}_{4} \mathrm{~F}_{6}$ is only equivalent to $1 / 1,000,000$ of carbon dioxide and 1/870,000 of octafluorocyclobutane; 3 ) higher aspect ratio. Hexafluorobutadiene is suitable for the extremely narrow line width process, and its aspect ratio can be up to 10 while the aspect ratio of octafluorocyclobutane is only 3; 4) higher selectivity. It only etches silicon oxide membrane without affecting the photoresist, silicon membrane or nitride membrane. Hexafluorobutadiene $\left(\mathrm{C}_{4} \mathrm{~F}_{6}\right)$ is 4.5 times the selectivity of carbon tetrafluoride $\left(\mathrm{CF}_{4}\right)$, while octafluorocyclobutane $\left(\mathrm{C}_{4} \mathrm{~F}_{8}\right)$ is 4 times the selectivity of carbon tetrafluoride $\left(\mathrm{CF}_{4}\right)$.

Recently, there are several companies focus on the research and development of hexafluorobutadiene, such as Ausimont of Italy, Kanto electrification of Japan, Asahi Glass, Dakin, Russia NITs Medkhim, United States PCBU SERVICES INC. However, only Ausimont and Kanto electrification have the capacity of tons productive scale. With the increasing demand of very large scale integrated circuit and the attention to greenhouse gases, it

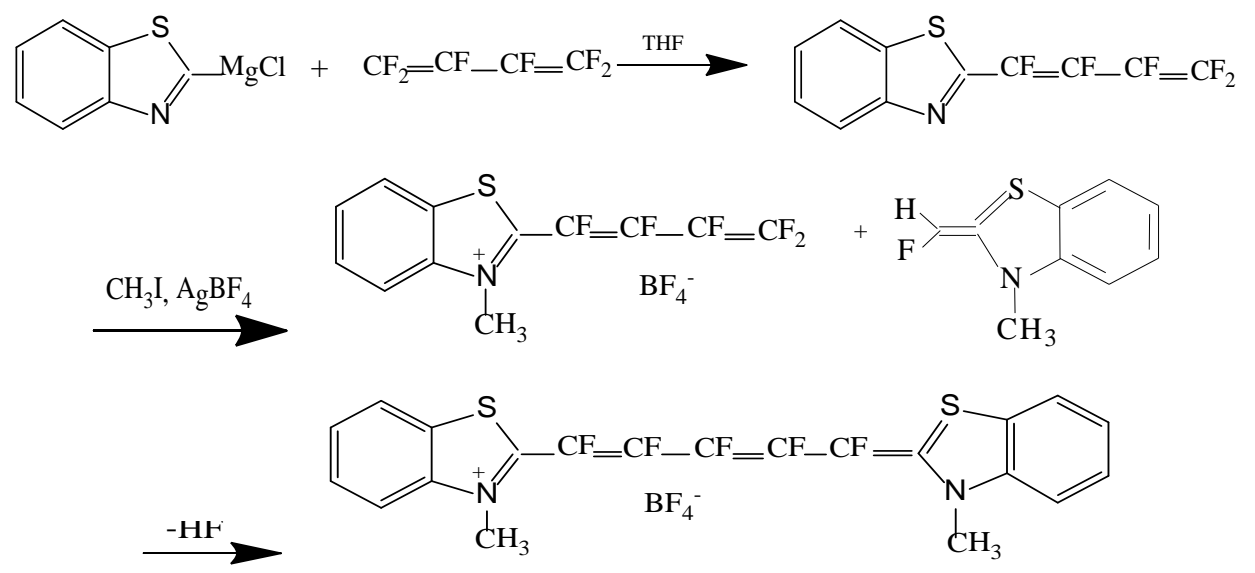

Scheme 1. The synthesis process of the flooring system into the cyanine dyes via reaction of perfluorobutadiene and benzothiazole. 
is foreseeable that hexafluorobutadiene, which has the characteristics of the best etching effect and environmental friendly, will become the leading product and will be widely used in the laser etching agent market.

\section{The Synthesis of Hexafluorobutadiene}

\subsection{Using 1,2-Difluoro-Dichloroethylene ( $\mathrm{CFCl}=\mathrm{CFCl})$ as Raw Material}

In 1956, Ruh [12] firstly prepared hexafluorobutadiene using 1,2-difluoro-dichloroethylene as raw materials. The autoclave was charged with 1,2-difluoro-dichloroethylene, and then heated to $275^{\circ} \mathrm{C}$. The reaction was conducted in presence of mercury salts catalyst for $6 \mathrm{~h}$, then the reaction mixture was distilled to obtain 1,3,4,4-tetrafluorotetrachloro-1-butene, and the yield was $87.4 \%$ (mol). Thereafter, addition reaction between the above product and chlorine was conducted in presence of photocatalyst to get 1,1,2,3,4,4-hexachloro-tetrafluorobutane, and the yield was $99.4 \%$. After that the 1,1,2,3,4,4-hexachloro-tetrafluorobutane and $\mathrm{SbF}_{3} \mathrm{Cl}_{2}$ were added to the autoclave and stirred at $250^{\circ} \mathrm{C}$ for $5 \mathrm{~h}$, then1,2,3,4-tetrachloro-hexafluorobutane was generated and the yield was 89.6\%. At last, 1,2,3,4-tetrachloro-hexafluorobutane was dissolved in anhydrous ethanol in a glass bottle with zinc powder to act dechlorination reaction. Hexafluorobutadiene was obtained and the yield was $93.5 \%$. The specific reaction equations were as follows:

$$
\begin{aligned}
& 2 \mathrm{CFCl}=\mathrm{CFCl} \rightarrow \mathrm{CFCl}=\mathrm{CF}-\mathrm{CFCl}-\mathrm{CFCl}_{2} \\
& \mathrm{CFCl}=\mathrm{CF}-\mathrm{CFCl}-\mathrm{CFCl}{ }_{2}+\mathrm{Cl}_{2} \rightarrow \mathrm{CFCl}_{2}-\mathrm{CFCl}-\mathrm{CFCl}-\mathrm{CFCl}_{2} \\
& \mathrm{CFCl}_{2} \text {-CFCl-CFCl-CFCl }{ }_{2}+\mathrm{SbF}_{3} \mathrm{Cl}_{2} \rightarrow \mathrm{CF}_{2} \mathrm{Cl}-\mathrm{CFCl}-\mathrm{CFCl}-\mathrm{CF}_{2} \mathrm{Cl} \\
& \mathrm{CF}_{2} \mathrm{Cl}-\mathrm{CFCl}-\mathrm{CFCl}-\mathrm{CF}_{2} \mathrm{Cl}+\mathrm{Zn} \rightarrow \mathrm{CF}_{2}=\mathrm{CF}-\mathrm{CF}=\mathrm{CF}_{2}+\mathrm{ZnCl}_{2}
\end{aligned}
$$

William T. Miller [13] reacted 1,2-difluoro-dichloroethylene with fluorine under 0.9 to $1.0 \mathrm{MPa}$ at room temperature for $26 \mathrm{~h}$, then1,2,3,4-tetrachloro-hexafluorobutane was obtained directly and the yield was about 51\% (mol). Thereafter, the above product and zinc powder were mixed in the diethylene glycol monobutyl ether, and the 1,2,3,4-tetrachloro-hexafluorobutane was dechlorinated directly to prduce hexafluorobutadiene. The equation was as follows:

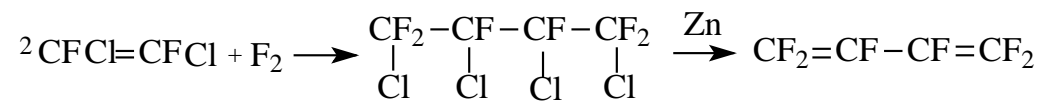

Since this method has the disadvantages of harsh reaction conditions, lower yield and poisonous and highly corrosive materials, there is no application of this method in industry yet.

\subsection{With Chlorotrifluoroethylene $\left(\mathrm{CF}_{2}=\mathrm{CFCl}\right)$ as Raw Material}

In 1957, Haszeldine [14] prepared hexafluorobutadiene using chlorotrifluoroethylene as raw material. The reaction firstly proceeded at $35^{\circ} \mathrm{C}$ to $40^{\circ} \mathrm{C}$ to give 1,2-dichloro-1,2,2-trifluoro-1-iodoethane and 2,2-dichloro-1,1, 2-trifluoro-1-iodoethane, and the yield was 97\%. Then 1,2-dichloro-1,2,2-trifluoro-1-iodoethane was purified and mixed with the same amount of mercury. Under UV irradiation for 48h, 1,2,3,4-tetrachloro-hexafluorobutane was obtained, and the yield was 95\%. After that, hexafluorobutadiene was got through the dechlorination reaction between the above product and zinc powder in ethanol solution, the yield was $98 \%$. The detailed reaction equations were as follows:

$$
\begin{aligned}
& \mathrm{CF}_{2}=\mathrm{CFCl}+\mathrm{IC} 1 \rightarrow \mathrm{CF}_{2} \mathrm{Cl}-\mathrm{CFClI} \\
& 2 \mathrm{CF}_{2} \mathrm{Cl}-\mathrm{CFClI}+\mathrm{Hg} \rightarrow \mathrm{CF}_{2} \mathrm{Cl}-\mathrm{CFCl}-\mathrm{CFCl}-\mathrm{CF}_{2} \mathrm{Cl}+\mathrm{HgI}_{2} \\
& \mathrm{CF}_{2} \mathrm{Cl}-\mathrm{CFCl}-\mathrm{CFCl}-\mathrm{CF}_{2} \mathrm{Cl}+2 \mathrm{Zn} \rightarrow \mathrm{CF}_{2}=\mathrm{CF}-\mathrm{CF}=\mathrm{CF}_{2}+2 \mathrm{ZnCl}_{2}
\end{aligned}
$$

William. T. Miller [13] decomposed trifluorochloroethylene in Pyrex tube under normal pressure at $550^{\circ} \mathrm{C}$ to generate 1,2-dichloro-hexafluorocyclobutane and 3,4-dichloro-hexafluoro-1-butene, the conversion was about $36.2 \%$. Because of having similar boiling point, the above products were directly added into a glass tube without separation to react with liquid chlorine. Under the light of $200 \mathrm{w}$ at room temperature for $24 \mathrm{~h}, 3$,4-dichlorohexafluoro-1-butene converted to 1,2,3,4-tetrachloro-perfluorobutane with the yield of $15.16 \%$ (mol). The reaction products was separated to obtain 1,2,3,4-tetrachloro-hexafluorobutane and l,2-dichloro-hexafluorocyclobutane. Finally, 1,2,3,4-tetrachlorohexafluorobutane was dechlorinated using zinc powder in ethanol to get hexafluorobutadiene. The reaction process was as follows: 


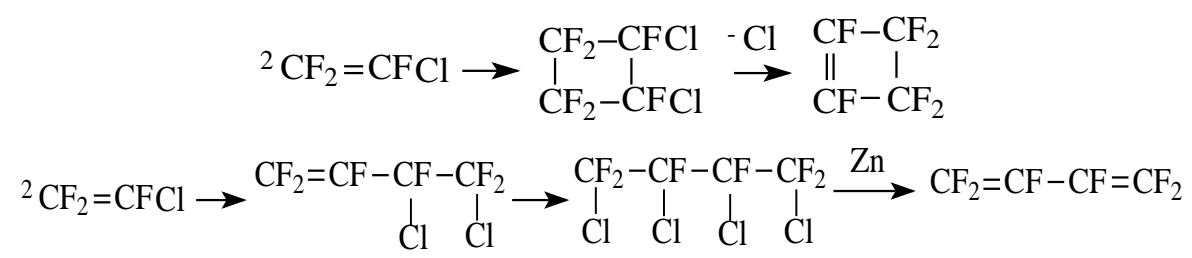

The generated 1,2-dichlorohexafluorocyclobutane is dehydrogenized using zinc powder in ethanol to get hexafluorocyclobutene [15]. D. Young [16] investigated the reaction of 1,2,3,4-tetrahydro-perfluorobutane and hydrogen at $250^{\circ} \mathrm{C}-300^{\circ} \mathrm{C}$ for $21.5 \mathrm{~h}$ under the pressure of $280 \mathrm{psig}$ in the presence of iodine catalyst, and the yield of product 1,2,3,4-tetrahydroperfluorobutane was more than $90 \%$. Thereafter, the product was distillated under reduced pressure and added into Vycor tube which contained a small amount of $\mathrm{H}_{2} \mathrm{O}$ and excessive chlorine, after irradiation of $100 \mathrm{w}$ tungsten filament lamp for 85 h, 1,2,3,4-tetrachloridehexafluorobutane and a handful of impurities were obtained. The 1,2,3,4-tetrachloridehexafluorobutane was separated from the mixtures after washing with alkaline, and then dechlorinated with zinc powder in ethanol. The reaction equations were as follows:

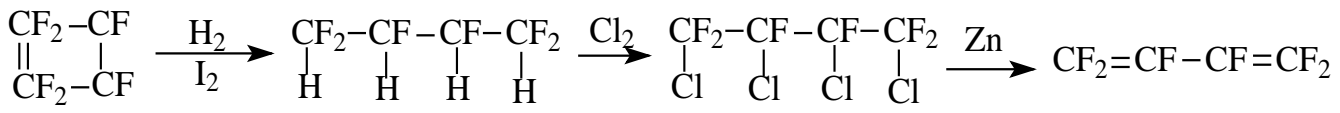

Veeraraghavan [17] developed a one-step synthetic method of hexafluorobutadiene using chlorotrifluoroethylene as raw materials. In the presence of various salt catalysts, reactions of trifluorochloroethylene and trifluorobromoethylene were studied. Reactions using copper salts catalyst and iron salts catalyst were preferable. Specific steps were presented as follows: Three necks' bottle was charged with zinc powder and anhydrous DMF, after cooling of dry ice, trifluorobromoethylenee was added slowly. Then, reaction system was heated up to $70^{\circ} \mathrm{C}$, and trifluoroethene zinc-bromine was formed after $1 \mathrm{~h}$. Under the condition of $0^{\circ} \mathrm{C}-5^{\circ} \mathrm{C}, 100 \mathrm{mmHg}$ vacuum and high purity nitrogen flow, displacement reaction was conducted by slowly adding iron salt $\left(\mathrm{FeCl}_{3}\right.$ or $\mathrm{FeBr}_{3}$ ) or copper salt $\left(\mathrm{Cu}(\mathrm{OTf})_{2}\right.$ or $\left.\mathrm{Cu}(\mathrm{OAc})_{2}\right)$. The generated gas was collected by a refrigerant of $-78^{\circ} \mathrm{C}$. Lastly, reaction system was heated up to $40^{\circ} \mathrm{C}$ and keep stirring for $2 \mathrm{~h}$ in order to discharge all the produced gas. The total yield was between $62 \%$ and $70 \%$. Specific process was as follows:

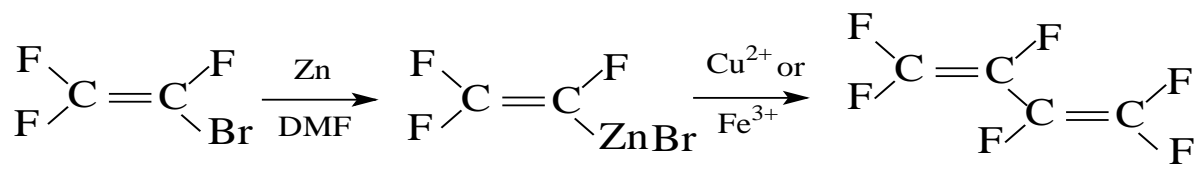

Robertovich [18] synthesized perfluorobutadiene in the presence of $\mathrm{PdCl}_{2}(\mathrm{PhCN})_{2}$ and three p-phenyl phosphine $\mathrm{p}\left(\mathrm{o}-\mathrm{CH}_{3} \mathrm{C}_{6} \mathrm{H}_{5}\right)$ as catalyst at $50^{\circ} \mathrm{C}-60^{\circ} \mathrm{C}$ by trifluorochloroethylene directly dechlorination with excessive zinc powder, and the maximum yield was $34 \%$.

Wang Yi [19] add the 1,1,2-tribromo-trifluoroethane which was synthesized by bromo-trifluoroethylene and bromine slowly into the mixture of excessive zinc powder and $\mathrm{DMF}$ at $50^{\circ} \mathrm{C}-70^{\circ} \mathrm{C}$, then the mixtures was heated up to $80^{\circ} \mathrm{C}-90^{\circ} \mathrm{C}$, and maintained for $1 \mathrm{~h}$. After the mixture was cooled to $0^{\circ} \mathrm{C}-5^{\circ} \mathrm{C}$, a solution of ferric trichloride and DMF was added. The generated hexafluorobutadiene is cooled at $-25^{\circ} \mathrm{C}$, with total yield of $42.12 \%$.

In the above synthetic routes, many serious environmental pollutions exist due to the using of poisonous and harmful materials during the dehalogenation and coupling reactions of 1,2-dichloro-1,2,2-trifluoro-1-ethyl iodide, such as acetic anhydride and iodine chloride. In addition, utilization rate is low. Meanwhile, dechlorination reaction products at the last step contain a lot of unreactive chlorine compounds, which brought greater difficulty to subsequent purification. However, this synthesis route is one of the earlier developed and mature route and the raw materials is cheap, so that some companies in Russia and Japan established tons scale industrial production devices using this method to product hexafluorobutadiene. Although the one-step method had the advantages of simple operation and wide raw material sources, the condition was rigorous and not easy to control. So far it is confined to the laboratory synthesis, but it has a good industrialization prospect if several key problems will be solved. 


\subsection{With Trichloroethylene as Raw Material}

Vito Tortelli et al. [20] synthesized $\mathrm{C}_{4} \mathrm{H}_{2} \mathrm{~F}_{2} \mathrm{Cl}_{6}$ by reacting trichloroethylene (TCE) and fluorine diluted with 10 times helium in autoclave until mole ratio of TCE and fluorine was 6.6:1, the flow rate of fluorine was $1 \mathrm{Nl} / \mathrm{h}$, the conversion rate of TCE is $24 \%$ and selectivity of $\mathrm{C}_{4} \mathrm{H}_{2} \mathrm{~F}_{2} \mathrm{Cl}_{6}$ is $60 \%$. Under the condition of reaction temperature less than $35^{\circ} \mathrm{C}$, the reaction of $\mathrm{C}_{4} \mathrm{H}_{2} \mathrm{~F}_{2} \mathrm{Cl}_{6}$ and $20 \% \mathrm{NaOH}$ solution was catalyzed with methyltrioctylammonium chloride by strongly stirring for $8 \mathrm{~h}$ to obtain 1,2,3,4-tetrachloro-difluoro-butadiene, and the yield was 93\%. Then the mixture of the above product, fluorine and helium were added in $50 \mathrm{ml}$ autoclave which was charged of 50.1 gram $\mathrm{CF}_{3} \mathrm{OCFClCF}_{2} \mathrm{Cl}$, the flow rates of 1,2,3,4-tetrachloro-difluoro-butadiene, fluorine and helium were $9.4 \mathrm{~g} / \mathrm{h}, 9.4 \mathrm{Nl} / \mathrm{h}$ and $0.75 \mathrm{Nl} / \mathrm{h}$ respectively. The reaction proceed at $10^{\circ} \mathrm{C}$ for $1 \mathrm{~h}$, the conversion of 1,2,3,4-tetrachloro-difluoro-butadiene was $97.8 \%$, and selectivity of 1,2,3,4-tetrachloro-perfluorobutane (CFC316) was $64 \%$. At last, hexafluorobutadiene was formed by reaction of 1,2,3,4-tetrachloro-perfluorobutane with zinc powder in 2-propanol, the yield was 95\%, while overall yield in the process of TCE was $33.92 \%$. Specific process was as follows:

$$
\begin{aligned}
& 2 \mathrm{CHCl}=\mathrm{CCl}_{2}+\mathrm{F}_{2} \rightarrow \mathrm{C}_{4} \mathrm{H}_{2} \mathrm{~F}_{2} \mathrm{Cl}_{6} \\
& \mathrm{C}_{4} \mathrm{H}_{2} \mathrm{~F}_{2} \mathrm{Cl}_{6} \rightarrow \mathrm{CFCl}=\mathrm{CCl}-\mathrm{CCl}=\mathrm{CFCl} \\
& \mathrm{CFCl}=\mathrm{CCl}-\mathrm{CCl}=\mathrm{CFCl}+\mathrm{F}_{2} \rightarrow \mathrm{CF}_{2} \mathrm{Cl}-\mathrm{CFCl}-\mathrm{CFCl}-\mathrm{CF}_{2} \mathrm{Cl} \\
& \mathrm{CF}_{2} \mathrm{Cl}-\mathrm{CFCl}-\mathrm{CFCl}-\mathrm{CF}_{2} \mathrm{Cl}+\mathrm{Zn} \rightarrow \mathrm{CF}_{2}=\mathrm{CF}-\mathrm{CF}=\mathrm{CF}_{2}+\mathrm{ZnCl}_{2}
\end{aligned}
$$

\subsection{With Tetrafluoroethylene $\left(\mathrm{CF}_{2}=\mathrm{CF}_{2}\right)$ as Raw Materials}

The route of using tetrafluoroethylene as main raw material is divided into two steps: the first step is that tetrafluoroethylene react with iodine or bromine to generate 1,2-dihalo -tetrafluoroethane, and then telomeric reaction between 1,2-dihalo-tetrafluoroethane and tetrafluoroethylene is conducted under certain temperature and pressure to produce a series of $\alpha, \omega$-dihalo-perfluoroalkanes; The second step is that the separated 1,4-dihalo-octafluorobutane dehalogenate to generate hexafluorobutadiene.

\subsubsection{Synthesis of 1, 4-Dihaloperfluorobutane}

The earliest report of synthesis of diiodoperfluoroalkanes was by Haszeldine in 1951 [21] and after that, large research efforts had been focused on this issue because of the increasing industrial demand. Dindi Hasan and Hagedorn [22] used tetrafluoroethylene and 1,2-diiodotetrafluoroethane to produce diiodoperfluoroalkanes, the total conversion of 1,2-diiodotetrafluoroethane reached $96 \%$ after 12 - 20 hours reaction under $245^{\circ} \mathrm{C}$ and 3.65 3.86 Mpa. Catalysis telomerization reaction was also developed [23], using benzoyl peroxide as catalyst; after 26 hours reaction under $80^{\circ} \mathrm{C}, 650$ psig, the mixture of $\mathrm{I}(\mathrm{C} 2 \mathrm{~F} 4)_{\mathrm{n}} \mathrm{I}(\mathrm{n}=1,2,3,4)$ was acquired. Zhang Zongli [24] using $\mathrm{Cu}$ as catalyst, synthesized diiodoperfluoroalkanes by telomerization method with tetrafluoroethylene and 1,2-diiodotetrafluoroethane; after 4 hours under $260^{\circ} \mathrm{C}$, the conversion reached $57 \%$, the selectivity reached $75 \%$. V. Tortelli and C. Tonelli [25] has developed a one step route in which tetrafluoroethylene and iodine was used to synthesize 1,2-diiodotetrafluoroethane at first, then 1,2-diiodotetrafluoroethane continued to react with superfluous tetrafluoroethylene. Suzuki Kaichirou [26] synthesized diiodoperfluoroalkanes by thermal deiodination reaction of 1,2-diiodotetrafluoroethane under $250^{\circ} \mathrm{C}$, the conversion of 1,2-diiodotetrafluoroethane was $70 \%$. Overall, thermal deiodination reaction and telomerization are currently the prevailing methods to synthesize DIPFAs. However, both methods need 1,2-diiodotetrafluoroethane as raw material.

Thermal pyrolysis: $\mathrm{ICF}_{2} \mathrm{CF}_{2} \mathrm{I} \rightarrow \mathrm{I}\left(\mathrm{C}_{2} \mathrm{~F}_{4}\right)_{\mathrm{n}} \mathrm{I}+(\mathrm{n}-1) \mathrm{I}_{2}$

Telomerization: $\mathrm{ICF}_{2} \mathrm{CF}_{2} \mathrm{I}+(\mathrm{n}-1) \mathrm{CF}_{2} \mathrm{CF}_{2} \rightarrow \mathrm{I}_{(}\left(\mathrm{C}_{2} \mathrm{~F}_{4}\right)_{\mathrm{n}} \mathrm{I}$

\subsubsection{Synthesis of Hexafluorobutadiene}

1,4-diiodooctafluorobutane separated from homologue of diiodoperfluoroalkanes could be transformed into hexafluorobutadiene by the two methods: one is that 1,4-diiodooctafluorobutane and a certain metal like $\mathrm{Zn}$ or Mg deiodinate in protic solvent to produce hexafluorobutadiene; The other is that 1,4-diiodooctafluorobutane react with Grignard reagent in aprotic solvents to get hexafluorobutadiene.

MIKI, Jun and YOSHIMI [27] synthesized hexafluorobutadiene by reacting $\mathrm{I}-\mathrm{CF}_{2}-\mathrm{CF}_{2}-\mathrm{CF}_{2}-\mathrm{CF}_{2}-\mathrm{I}$ and zinc 
powder in DMF, the process was as follow: $\mathrm{I}-\mathrm{CF}_{2}-\mathrm{CF}_{2}-\mathrm{CF}_{2}-\mathrm{CF}_{2}-\mathrm{I}$ was mixed with zinc powder , slowly heated to $120^{\circ} \mathrm{C}$ for 30 minutes, a mixture of DMF and $\mathrm{Zn}$ was droped into the reactants, and the reaction was kept moderate. Then gas mixture containg hexafluorobutadiene was obtained after 30 minutes, the content of hexafluorobutadiene was 65\%, and the yield was 53.66\%. In contrast, when perfluorochemical (such as FC-30) was added into the reaction as solvent and reaction proceed under $140^{\circ} \mathrm{C}$, the content of hexafluorobutadiene in the mixed gases is $88 \%$, and the overall yield of the process is $64.74 \%$. Reaction equations were as follows:

$$
\begin{aligned}
& 2 \mathrm{CF}_{2}=\mathrm{CF}_{2}+\mathrm{I}_{2} \rightarrow \mathrm{I}-\left(\mathrm{CF}_{2}\right)_{4}-\mathrm{I} \\
& \mathrm{I}-\left(\mathrm{CF}_{2}\right)_{4}-\mathrm{I}+\mathrm{Zn} \rightarrow \mathrm{CF}_{2}=\mathrm{CF}-\mathrm{CF}=\mathrm{CF}_{2}+\mathrm{ZnI}_{2}
\end{aligned}
$$

The above reaction has advantages of simple process and available raw materials, but once it was triggered, the reaction would appear some phenomena, such as releasing a large amount of heat, reacting violently, controlling difficultly, and producing a plenty of by-products, furthermore, the total yield of the products is relatively low. So far, it hasn't been found for industrialization.

Gianangelo synthesized hexafluorobutadiene in the following ways. At first, 1,4-diiodooctafluorobutane [28] or 1,4-dibromooctafluorobutane [29] and tetrahydrofuran (THF) were mixed, heated to boil, and Grignard reagent made from bromoethane and Mg with a concentration of 1 mole was slowly added, the reaction was controlled moderately. The generated gas was only hexafluorobutadiene, the yield was $71.6 \%$. By analysis, the solution still contained a small amount of hexafluorobutadiene, the overall yield was $96 \%$.

Hae-Seok Ji, et al. [30] reported that magnesium powder and a little of Grignard reagent with concentration of 1 mole were added into 1 litre toluene, the mole rate of magnesium powder to 1,4-diiodoperfluorobutane is 1.5:1, under strongly stirring, the mixture was heated to boil, and then slowly droped 400 grams of 1,4-dibro-moperfluorobutane in 3 hours, thereafter, product was collected using cold media with a temperature of $-40^{\circ} \mathrm{C}$. The weight of product was 178 grams. The content of hexafluorobutadiene was $96 \%$. The yield of hexafluorobutadiene was $94.93 \%$. Reaction equations were as follows:

$$
\begin{aligned}
& 2 \mathrm{CF}_{2}=\mathrm{CF}_{2}+\mathrm{Br}_{2} \rightarrow \mathrm{Br}-\left(\mathrm{CF}_{2}\right)_{4}-\mathrm{Br} \\
& \mathrm{Br}-\left(\mathrm{CF}_{2}\right)_{4}-\mathrm{Br}+\mathrm{C}_{2} \mathrm{H}_{5} \mathrm{MgBr} \rightarrow \mathrm{CF}_{2}=\mathrm{CF}-\mathrm{CF}=\mathrm{CF}_{2}+\mathrm{C}_{2} \mathrm{H}_{5} \mathrm{Br}+\mathrm{MgBr}_{2}
\end{aligned}
$$

Comparing to the dehalogenation reactions using metals, the reaction using Grignard reagent to get hexafluorobutadiene has the obvious advantages: moderate reaction conditions, low impurity content, relatively high yield and selectivity. However, products in the reaction using Grignard reagent contain the isomer of perfluorocyclobutane, whose boiling point is only higher $0.8^{\circ} \mathrm{C}$ than perfluorobutadinene, so that the products are purified with more difficultly. At the same time, using Grignard reagent as raw material had an extremely harsh using condition, that's to say it should be prepared at service times. It increased the difficulty of realizing industrial production to a certain extent, thus, the method hasn't been found in the industrial production. Although these synthesis methods had quite a few shortcomings, $\alpha, \omega$-diiodoperfluoroalkanes, which was an intermediate for many synthesis of useful fluorinated compound, was used extensively, in addition, it could obviously reduce the production cost of hexafluorobutadiene and made this method have extremely strong competitiveness.

\subsubsection{With Waste PTF as Raw Materials}

Considering the severe reaction conditions and using of the high purity tetrafluoroethylene monomer, a new synthesis method of 1,2-diiodotetrafluoroethane has been developed. The detail process is as follows: firstly, waste tetrafluoroethylene was pyrolyzed to obtain tetrafluoroethylene monomer at $500^{\circ} \mathrm{C}$ and $2 \mathrm{kPa}$ [31]. The conversion of waste tetrafluoroethylene pyrolysis reaction was 99.6\%, and the yield of tetrafluoroethylene monomer was $95.52 \%$. And then the pyrolysis gas, which also contained hexafluoropropylene and octafluorocyclobutane, directly reacted with iodine at $150^{\circ} \mathrm{C}$ and $1.2 \mathrm{MPa}$ without separation, and the conversion of iodine was $98.05 \%$, while the selectivity was $98.4 \%$. In terms of the conversion and selectivity of iodine, there was no essentially difference between the two means of using pyrolysis gas and high purity tetrafluoroethylene as raw material respectively.

Based on the above green synthesis process, a further study on the one-step synthesis method of $\alpha, \omega$-diiodoperfluoroalkanes [24] has been also developed. Preparation of 1,2-diiodotetrafluoroethane and synthesis of 1,4- 
diiodooctafluorobutane were conducted by one step reaction, which not only reduced the loss of materials, but also greatly shortened the reaction time and improved the yield of target product. Detail process is as follows: the autoclave was charged with iodine, solid copper powder and 1,2-diiodotetrafluoroethane as solvent, and then heated to $160^{\circ} \mathrm{C}$ to synthesize 1,2-diiodotetrafluoroethane. After iodine reacted completely by inletting into pyrolysis gas, $\mathrm{C}_{2} \mathrm{~F}_{4}$ was continuously fed to keep a certain pressure in the autoclave, and then the reaction proceed for 4 hours at $260^{\circ} \mathrm{C}$. After that the reaction temperature was reduced to $160^{\circ} \mathrm{C}$ and $\mathrm{C}_{2} \mathrm{~F}_{4}$ gas was continuously added to react with elemental iodine generated during thermal pyrolysis reaction. 1,2-diiodotetrafluoroethane in the product was separated by distillation to recycle as solvent. According to $\mathrm{I}\left(\mathrm{C}_{2} \mathrm{~F}_{4}\right) \mathrm{I}$, the total mole yield of 1,4-diiodooctafluorobutane was $68.15 \%$.

1,4-diiodooctafluorobutane, which was obtained by distillating from the above reaction product, reacted with the Grignard reagent to get hexafluorobutadiene through reactive-distillation process [32]. Specific reaction process was as follows: $400 \mathrm{ml}$ tetrahydrofuran was placed into the tower kettle with a thermocouple, Grignard reagent and tetrahydrofuran solution contained diiodooctafluorobutane were respectively added in the two dropping funnel, Grignard reagent was prepared with bromobenzene and $\mathrm{Mg}$ in the diethyl ether, and the addtion amount of Grignard reagent and tetrahydrofuran solution were $670 \mathrm{ml}$ (2.01 mol) and $454 \mathrm{~g}(1.0 \mathrm{~mol}) \mathrm{respec}-$ tively. Under the protection of nitrogen with a flow rate of $0.5 \mathrm{l} / \mathrm{h}$, tetrahydrofuran was heated to boil, the cooling temperature of tower top was maintained between $6^{\circ} \mathrm{C}-7^{\circ} \mathrm{C}$, and a certain return flow on the top of the tower was kept. After total reflux, Grignard reagent and diiodooctafluorobutane solution were droped slowly from the middle of distillation tower during 3 - $4 \mathrm{~h}$, and the mass of $164 \mathrm{~g}$ of crude product hexafluorobutadiene was got by collecting with a low temperature of $-90^{\circ} \mathrm{C}$ in cold trap. The conversion rate of 1,4-diiodooctafluorobutane was $99.53 \%$, the yield of hexafluorobutadiene was $96.75 \%$, and the selectivity was $97.2 \%$.

\section{Conclusion}

Hexafluorobutadiene $\left(\mathrm{C}_{4} \mathrm{~F}_{6}\right)$ is a new plasma etching agent which is used in the manufacture process of the large scale integrated circuit and memory chips with high speed and high capacity. It is also a synthetic monomer of many materials, such as a new type of fluorine resin, fluorine plastic and fluorine rubber. However, only Italy and Japan have the capacity of more than ton scale production of hexafluorobutadiene, which makes its market price high ( $\$ 500$ - $\$ 600 / \mathrm{kg}$ ) at present. So it has extremely good economic prospect to develop industrial production approach of hexafluorobutadiene as soon as possible. Among these several synthetic methods of hexafluorobutadiene, the synthetic method using trifluorochloroethylene as material is mainly route being used in industrial manufacture. This route has advantages of mature technology, raw material easy to get and simple operation, but the chlorine compound generating in the reaction and raw material trifluorochloroethylene all destroys the Ozone layer, and is prohibited to use in many countries. The strict requirement to the content of chlorine compound in hexafluorobutadiene makes the refinement of production become more difficult and the cost of production becomes higher. In the contrast, the route using tetrafluoroethylene as raw material has a lower costing of production because the 1,6-diiodoperfluorohexane and 1,8-diiodoperfluorooctane by-products also have a high price. Furthermore, the intermediates are iodine compounds, so that this route has none environmental problems. Now, the waste polytetrafluoroethylene using as raw material can further reduce the costing of hexafluorobutadiene production. If the restrictions of Grignard reagent application can be reduce, the route will have very good prospects for industrial application.

\section{References}

[1] Toshio, Y. and Takahiro, N. (2008) Coating Composition, Coating Formed Therfrom, Anti-Reflection Coating, Anti-Reflection Film, and Image Display Device. US7371786.

[2] Hsing-Yeh, P. and Willia, L. (2001) Preparation of Fluorinated Polymers. US6218464.

[3] Massimo, M. and Dario, S. (1999) Novelties and Prospects in the Synthesis of Perfluoropolyethers by Oxidative Polymerization of Fluoroolefins. Journal of fluorine Chemistry, 95, 19-25. http://dx.doi.org/10.1016/S0022-1139(98)00295-4

[4] Sun, W. and Wang, X. (2010) Soldering-Pan and Forming Method Thereof. CN101645408-A.

[5] Park, S., Cheong, J. and Park, S.S. (2008) Method for Fabricating Capacitor in Semiconductor Device. US2008081429-A1.

[6] Jun, M., Hitoshi, Y. and Hirozaku, A. (2003) Process for Production of Perfluoroalkadienes. US6610896. 
[7] Hung, H., Caulfield, J.P and Shan, H. (2003) Process for Etching Oxide Using Heafluorobutadiene or Related Fluorocarbons and Manifesting a Wide Process Window. US6602434.

[8] Rensmo, H., Keis, K., Lindström, H., et al. (1997) High Light-to-Energy Conversion Efficiencies for Solar Cells Based on Nanostructured ZnO Electrodes. Journal of Physical Chemistry B, 101, 2598-2601. http://dx.doi.org/10.1021/jp962918b

[9] Yagupolskii, L.M., Chernega, O.I., Kondratenko, N.V., et al. (2010) Synthesis of the First Representative of Dicarbonthiacyanine Dyes with Completely Fluorinated Polymethine Chain. Journal of Fluorine Chemistry, 131, 165-171

[10] Hung, R., Caulfield, J.P., Shan, H., et al. (2003) Highly Selective Oxide Etching Process Using Hexafluorobutadiene. US 6613691.

[11] Hung, H., Caulfield, J.P., Shan, H.Q., et al. (2003) Highly Selective Process for Etching Oxide over Nitride Using Hexafluorobutadiene. US 2003/0000913.

[12] Palmer, R.R. and Ralph, D. (1958) Preparation of Hexafluorobutadiene. GB798407.

[13] Miller, W.T. (1950) Polyunsaturated Fluoroolefins. US2668182.

[14] Haszeldine, R.N. (1962) Coupling of Halogenated Organic Compounds. US3046304.

[15] Harmon, J. (1943) Polyfluorocyclobutenes. US2436142.

[16] Young, D. (1960) Improvements in or Relating to the Preparation of 1,2,3,4-tetrahydroperfluorobutane and Perfluorobutadiene. GB839756.

[17] Veeraraghavan Ramachandran, P. and Venkat Reddy, G. (2008) Preparative-Scale One-Pot Syntheses of Hexafluoro-1,3-Butadiene. Journal of Fluorine Chemistry, 129, 443-446. http://dx.doi.org/10.1016/j.jfluchem.2008.01.015

[18] Robertovich, M.O. (2008) Method of Obtaining Hexafluorobutadiene. RU2340588.

[19] Wang, Y., Wang, Q.M., Shen, D.X., et al. (2012) Method for Preparing Hexafluorobutadiene-1,3. CN102399128.

[20] Tortelli, V., Millefanti, S. and Carella, S. (2010) Process for the Synthesis of Perfluorobutadiene. US2010/0280291.

[21] Haszeldine, R.N. (1951) Synthesis of Fluorocarbons, Perfluoroalkyl Iodides, Bromides and Chlorides, and Perfluoroalkyl Grignard Reagnts. Nature, 167, 139-140. http://dx.doi.org/10.1038/167139a0

[22] Dindi, H. and Hagedorn, J.J. (2004) Process for Manufacturing Diiodoperfluoroalkanes. US 006825389.

[23] Thiokol Chemical Corporation (US) (1973) Method of Making Alpha-Omega-Diiodoperfluoroalkanes. GB1301617.

[24] Zhang, Z.L., Zhu, J., Jing, X., et al. (2005) Method for Preparing Alpha, Omega Diiodoperfluo-Alkane. CN1686985.

[25] Tortelli, V. and Tonelit, C. (1990) Telomerization of Tetrafluoroethylene and Hexafluoropropene: Synthesis of Diiodoperfluoroalkanes. Journal of Fluorine Chemistry, 47, 199-217. http://dx.doi.org/10.1016/S0022-1139(00)82373-8

[26] Suzuki, K., Uchijima, Y., Munakata, S., et al. (1978) Preparation of 1, 4-diiodoperfluorobutane. JP53144507 (A).

[27] Jun, M. and Htoshi, Y. (2002) Process for Production of Perfluoroalkadienes. EP1247791.

[28] Bargigia, G. and Tortelli, V. (1987) Process for the Synthesis of Hexafluorobutadiene and of Higher Perfluoronated dienes. US4654448.

[29] Bargigia, G., Tortelli, V. and Tonelli, C. (1987) Process for the Synthesis of Perfluoroalkandiene. EP 0270956.

[30] Ji, H.S., Cho, O.J. and Ahn, Y.H. (2009) Method for Preparing Perfluoroalkandiene. US7504547.

[31] Zhu, J., Wang, B.H. and Liu, D.Z. (2013) Synthesis of 1,2-diiodotetrafluoroethane with Pyrolysis Gas of Waste Polyterafluoroethylene as Raw Material. Green Chemistry, 15, 1042-1047. http://dx.doi.org/10.1039/c3gc36880g

[32] Zhu, J., Liu, C., Wang, B.H., et al. (2010) Preparation Method of Hexafluorobutadiene. CN101774884. 
Scientific Research Publishing (SCIRP) is one of the largest Open Access journal publishers. It is currently publishing more than 200 open access, online, peer-reviewed journals covering a wide range of academic disciplines. SCIRP serves the worldwide academic communities and contributes to the progress and application of science with its publication.

Other selected journals from SCIRP are listed as below. Submit your manuscript to us via either submit@scirp.org or Online Submission Portal.
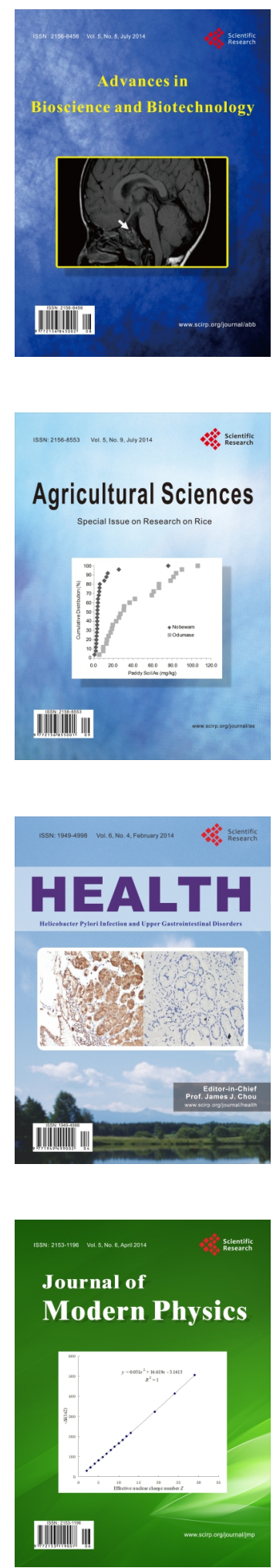
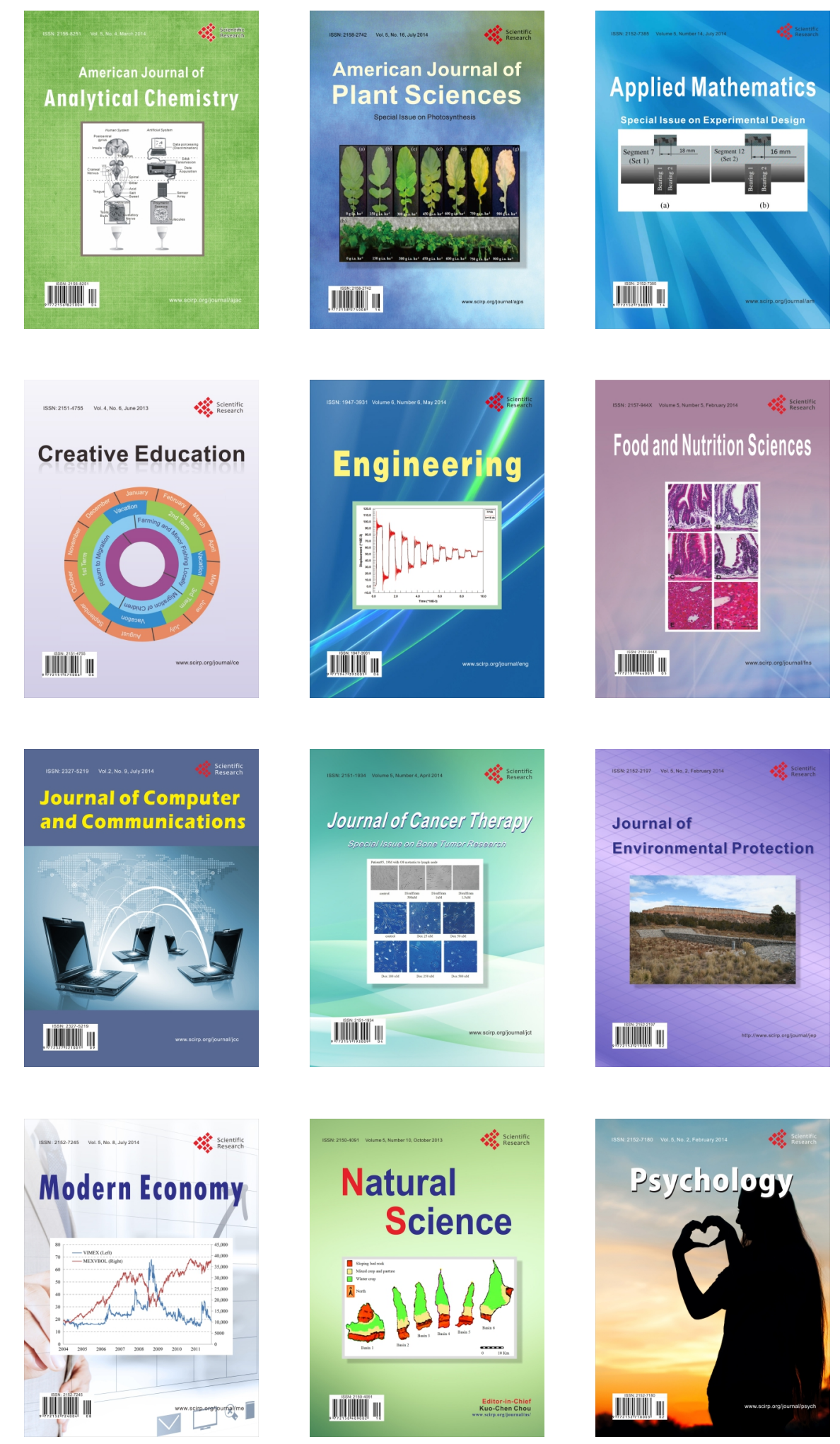